\title{
Decisões em projetos de investimentos: discussões acerca do método da TIR*
}

\author{
Decisions in Investment Projects: Discussions About the IRR Method
}

\author{
Renato Antonio Ferreira Filho, Andréa Ryba e Marcelo Kaminski Lenzi**
}

\begin{abstract}
Resumo: No âmbito da análise de viabilidade econômica de projetos, conhecimentos acerca das diversas maneiras de se mensurar o retorno do capital investido em um empreendimento são imprescindíveis para auxiliar a tomada de decisão. Um dos métodos mais tradicionais para isso é o cálculo da Taxa Interna de Retorno (TIR), amplamente difundido e utilizado há décadas. Entretanto, se faz necessário considerar as restrições para sua aplicação. Dessa forma, este trabalho tem por objetivo demonstrar a evolução das discussões acerca da aplicabilidade da TIR, suas limitações e aplicações, buscando embasar o leitor para a utilização da referida técnica. Para isto, contempla uma revisão bibliográfica pontuando os avanços no estudo sobre o tema que, de alguma maneira, contribuíram para as definições atuais acerca do método. Com isso, pode-se concluir que, embora os estudos aqui citados apontem para a consistência do método, é importante ressaltar a importância de sua combinação com outras técnicas, visando estabelecer uma análise que englobe as singularidades de cada projeto.
\end{abstract}

Palavras-chave: TIR; Projetos de Investimentos; Engenharia Econômica

\begin{abstract}
In the scope of economic feasibility analysis of projects, knowledge about the different ways of measuring the return of invested capital in an enterprise in a project is essential to aid decision making. One of the most traditional methods is the Internal Rate of Return (IRR), widely defused and used for decades. However, it is necessary to consider the restrictions to its application. That said, this paper aims to demonstrate the evolution of the discussions about the applicability of the IRR, its limitations, and applications, seeking to support the reader's use of this technique. For that, it contemplates a bibliographical revision evidencing the advances about the topic, which somehow contributed to the current terms and definitions about the method. With this, it can be concluded that, although the studies cited here point to the consistency of the approach, it is significant to emphasize the importance of its combination with other techniques, aiming to establish an analysis that encompasses the singularities of each project.
\end{abstract}

\footnotetext{
* Submissão: 12/06/2019 | Aprovação: 16/08/2020 | DOI: 10.5380/re.v42i78.67391

${ }^{* *}$ Respectivamente: (1) Quando do desenvolvimento do trabalho, aluno do curso de Engenharia Civil da UFPR, Brasil | E-mail: renatoaferreirafilho@yahoo.com.br | ORCID: 0000-0003-2597-4234 | (2) Professora do Departamento de Transportes da UFPR, Brasil | E-mail: andrea.ryba@ufpr.br | ORCID: 0000-0001-7257-9611 | (3) Professor do Departamento de Engenharia Química da UFPR, Brasil | E-mail: lenzi@ufpr.br | ORCID: 0000-0002-0103-9017
} 
Keywords: IRR; Investment Projects; Economic Engineering

JEL: O22; L70 


\section{Introdução}

Diante da busca constante pela maximização do retorno proveniente do investimento de Capital e diante de um amplo conjunto de opções oferecido pelo mercado brasileiro, como o tesouro direto, as aplicações bancárias, os fundos de investimento, as ações de empresas, o mercado imobiliário e até mesmo a iniciativa própria de abertura de um novo negócio, é primordial ter algum parâmetro para que se possam comparar as diversas possibilidades.

Nesse contexto, e de acordo com Ryba, Lenzi e Lenzi (2016, p. 93-94), a análise de viabilidade econômica e financeira é um dos estudos básicos a serem feitos pelo empreendedor e pelo investidor antes de iniciar um novo projeto, juntamente com as análises de critérios ditos imponderáveis. Desta forma, projetar o fluxo de caixa e saber avaliá-lo, sob um ponto de vista crítico, para depois investir, é um dos passos essenciais para o sucesso de novos empreendimentos.

Assim, as técnicas de análise de projetos de investimentos dispõem de vários instrumentos que nada mais são do que métricas que possibilitam avaliar o quão atrativo é determinado projeto. Além disso, viabilizam a comparação entre diversas opções de investimentos, sob uma ótica fundamentalmente econômica e financeira, para então se ponderar a sua rentabilidade ao risco assumido, produzindo uma análise completa e sólida de viabilidade.

Dentre os muitos instrumentos de análise de investimentos, podem ser citados o lucro projetado, o método do valor anual, a exposição de capital, a TIRM (Taxa Interna de Retorno Modificada), a TIR (Taxa Interna de Retorno), o PayBack e o VPL (Valor Presente Líquido), sendo os três últimos os mais utilizados (Casarotto Filho; Kopittke, 1994; Ryan; Ryan, 2002). Alguns são mais simples, outros um tanto quanto mais elaborados, entretanto, todos têm um único objetivo: avaliar o quão interessante é um projeto a ser desenvolvido e servir de base para a sua aceitação ou rejeição.

Assumindo a TIR como um método de ampla utilização na análise de projetos de investimentos e considerando as diversas abordagens matemáticas utilizadas por diversos estudiosos do tema, tem-se como objetivo desse trabalho a apresentação da evolução das teorias relacionadas ao método da TIR, bem como suas limitações. Para tanto, serão apresentados, de forma objetiva, os trabalhos que delinearam o desenvolvimento do tema em questão, de forma a fundamentar e orientar o leitor na escolha do método a ser utilizado na tomada de decisão. Serão 
abordadas questões tais como os possíveis resultados múltiplos até a suposta consideração de reaplicação dos fluxos de caixa intermediários na mesma taxa calculada, que estaria implícita nas considerações do método. $\mathrm{O}$ debate iniciou-se no século passado (Solomon, 1956; Renshaw, 1957) e prolonga-se até a atualidade com vários estudos com distintas abordagens (Cheremushkin, 2012; Arjunan; Kannapiran, 2017), o que será apresentado a seguir.

\section{O desenvolvimento dos métodos de análise de viabilidade econômica}

Historicamente, atividades de crédito precederam a cunhagem de dinheiro por cerca de dois mil anos. Antigos documentos sumérios que datam do ano 3000 a.C. comprovam o uso sistemático de crédito baseado em empréstimo de grãos e de metais (mensurados em volume e em peso, respectivamente), frequentemente remunerados com juros (Homer; Sylla, 2005).

Os primeiros registros do conhecimento de juros compostos remontam à época do período babilônico, entre 1800-1600 a.C., constatado em registros históricos de tabelas com somas de exponenciais feitas na época, que foram utilizadas para auxiliar nos cálculos (Neugebauer, 1957). Embora o conceito fosse utilizado desde a antiguidade, a lei romana e a igreja medieval consideravam a aplicação de juros compostos abominável, o que acabou impactando negativamente no desenvolvimento do tema (Parker, 1968; Geisst, 2013). Mesmo com essas proibições, encontram-se em livros de matemática de Leonardo Fibonacci, que datam do século XIII, conteúdos sobre juros compostos (Parker, 1968), de maneira que o conhecimento não deixou de ser passado para as gerações seguintes.

Com o passar dos anos, as atividades econômicas foram se desenvolvendo e estudos deram início ao desenvolvimento das metodologias que hoje são conhecidas como de fluxos de caixa descontados. Em 1582, Simon Stevin apresentou o que chamou de regra geral para encontrar a mais rentável entre duas ou mais opções, o que é conhecido hoje como Valor Presente Líquido, porém foi inicialmente aplicado apenas em empréstimos (Parker, 1968).

Outro momento histórico a ser considerado ocorreu em 1843, quando Joseph M. Price preparou o mais antigo conhecido conjunto de "tabelas de dívida" (Soldofsky,1966), que pode ser utilizado para se encontrar o rendimento até a maturidade de uma dívida, ou seja, a taxa de juros que iguala o valor atual da 
emissão de um título de dívida com a soma dos fluxos de caixa futuros. Uma aplicação particular do que posteriormente seria denominada Eficiência Marginal do Capital ou Taxa Interna de Retorno (Parker, 1968).

Embora os conceitos já estivessem presentes na literatura, é importante observar que até então eles foram utilizados apenas em atividades puramente financeiras, o que perdurou até o século XIX. O provável motivo para isso era que os investimentos em projetos até esse período eram relativamente pequenos, sendo que não se sentia a necessidade de aplicar conceitos mais sofisticados de análise de viabilidade (Parker, 1968). Esse ponto começou a ser mudado com a chegada das construções de ferrovias.

Com as construções ferroviárias, em que era necessário alocar uma grande quantia de capital num projeto, muito antes de qualquer recebimento, surgiu a necessidade de se ponderar o tamanho dos investimentos com o volume das receitas e, ainda, com o prazo de duração desses fluxos. Assim, em 1887, o Engenheiro Civil americano A. M. Wellington antecipou algumas das ideias atuais da análise de custo de capital (Wellington, 1887).

Wellington (1887) elaborou um quadro comparativo que demonstra o montante da aplicação de $\$ 1$ em períodos de tempo que variam de 1 a 100 anos, rendendo taxas de aplicação que vão desde 3 até $10 \%$ a.a. Com isso o engenheiro deixou evidente a importância de se levar em consideração o valor do dinheiro no tempo ao se lançar em projetos de longo prazo, como o de uma ferrovia. Considerando esses fatores, Wellington (1887) concluiu que para planejar a execução de uma obra daquele porte deveria ser considerado como horizonte de planejamento do projeto um prazo entre 3 e 10 anos. Isso porque, em se tratando de tempos maiores, o custo do capital investido seria muito grande para tornar o empreendimento rentável, numa escala de tempo adequada (Wellington, 1887). Pode-se perceber claramente uma extrapolação de um conceito que, até então, era puramente financeiro para a área de viabilidade de um projeto de engenharia.

A partir de então, os estudos de viabilidade e a tentativa de desenvolver ferramentas que permitissem mensurar adequadamente a rentabilidade de projetos passaram a ser recorrentes nos trabalhos de diversos autores, como Böhm-Bawerk (1903), Marshall (1907) e Fisher (1907). Böhm-Bawerk (1903) usou a abordagem do Valor Presente Líquido (VPL) num exemplo da aquisição de uma casa em várias 
prestações, demonstrando que o valor atual do "sacrifício" total, que será gasto pelo comprador, deve ser o valor de todas as parcelas descontadas para o presente.

Com o passar do tempo, percebe-se que o conceito de valor presente de um fluxo de caixa foi se consolidando na literatura, embora não com essa denominação. Contudo, nota-se que até o século XIX, a técnica estava sendo utilizada apenas para atualizar fluxos futuros, descontando-os. Foi quando em 1907, o britânico Alfred Marshall pontuou que o valor de um projeto, em um dado momento no tempo, poderia ser calculado acumulando os esforços (saídas de caixa) e as satisfações (entradas de caixa), que já ocorreram, considerando uma correção justa de juros e descontando as entradas e saídas de caixa esperadas no futuro, considerando também o risco de falha do projeto. Marshall (1907) concluiu ainda, que o investidor deveria atuar, nesse caso, apenas quando sua margem de rentabilidade requerida fosse atingida, considerando um desconto relativo ao risco do empreendimento.

Ainda em 1907, seguindo na linha de desenvolvimento de uma maneira eficaz de analisar a viabilidade de projetos, Irving Fisher sugeriu métodos a serem aplicados nos fluxos de caixa dos projetos que possibilitassem concluir se estes eram economicamente viáveis ou, então, que serviriam de apoio para selecionar um entre vários projetos. Assim, Fisher (1907) comparou três possibilidades de usos da terra para ilustrar suas metodologias: (A) atividade agrícola, que o autor caracterizou como um investimento que gera fluxos de caixa regulares e constantes ao longo do tempo; (B) propósitos florestais, que no início não gera um fluxo de caixa considerável, entretanto, com o decorrer do tempo os fluxos tendem a ser muito maiores do que os relativos à atividade agrícola; (C) propósitos de mineração, em que os maiores fluxos de caixa acontecem no início e consequentemente entram em uma queda progressiva.

A fim de dar suporte para que o dono da terra conseguisse optar por um dentre esses fluxos tão distintos de maneira a levar em consideração a maior geração de valor, o primeiro método que Fisher (1907) sugeriu que seja selecionado o projeto que contenha o maior valor presente, utilizando uma taxa de desconto equivalente à taxa de juros de mercado. Nesse momento, a metodologia do valor presente estava sendo amplamente difundida.

Fisher (1907) deixou muito claro que a escolha entre uma possibilidade ou outra era intimamente influenciada pela taxa de juros adotada, o que poderia 
determinar qual seria o projeto com maior valor presente. Prosseguindo com sua linha de raciocínio, Fisher (1907) deu valores aos fluxos de caixa, que estão relacionados na TABELA 1.

Tabela 1 - Fluxos de caixa anuais

\begin{tabular}{c|c|c|c}
\hline Período & Propósitos Florestais & Mineração & Atividade Agrícola \\
\hline Ano 1 & $\$ 0$ & $\$ 2000$ & $\$ 450$ \\
\hline Ano 2 & $\$ 0$ & $\$ 1800$ & $\$ 450$ \\
\hline Ano 3 & $\$ 300$ & $\$ 1600$ & $\$ 450$ \\
\hline Ano 4 & $\$ 400$ & $\$ 1400$ & $\$ 450$ \\
\hline Ano 5 & $\$ 500$ & $\$ 1200$ & $\$ 450$ \\
\hline Ano 6 & $\$ 500$ & $\$ 1000$ & $\$ 450$ \\
\hline Ano 7 & $\$ 500$ & $\$ 800$ & $\$ 450$ \\
\hline$\vdots$ & $\vdots$ & $\vdots$ & $\vdots$ \\
\hline Ano n & $\$ 500$ & $\$ 0$ & $\$ 450$ \\
\hline
\end{tabular}

Fonte: Adaptado de Fisher (1907).

Fisher (1907) prosseguiu com o estudo do impacto da taxa adotada para descontar os fluxos no resultado obtido do valor presente (TABELA 2). Percebeuse que taxas de juros de maior magnitude dão mais ênfase a investimentos com entradas de caixa consideráveis a curto prazo, enquanto que taxas de juro menores fazem o oposto. Fisher (1907) seguiu, então, demonstrando maneiras diferentes de estudar um impacto com essas mesmas características.

Tabela 1 - Impacto da variação da taxa de desconto no valor presente dos fluxos de caixa

\begin{tabular}{c|r|r|r}
\hline \multirow{2}{*}{$\begin{array}{c}\text { Taxa de Desconto } \\
(\% \text { a.a. })\end{array}$} & \multicolumn{3}{|c}{ Valor Presente do Fluxo } \\
\cline { 2 - 4 } & \multicolumn{1}{|c|}{$\begin{array}{c}\text { Propósitos } \\
\text { Florestais }\end{array}$} & $\begin{array}{c}\text { Propósitos de } \\
\text { Mineração }\end{array}$ & $\begin{array}{c}\text { Atividade } \\
\text { Agrícola }\end{array}$ \\
\hline 5 & $\$ 8820$ & $\$ 9110$ & $\$ 9000$ \\
\hline 4,5 & $\$ 9920$ & $\$ 9280$ & $\$ 10000$ \\
\hline 4 & $\underline{\$ 11300}$ & $\$ 11250$ & $\$ 9450$ \\
\hline
\end{tabular}

Fonte: adaptado de Fisher (1907).

Considerando agora a comparação entre apenas duas possibilidades de investimento, a saber, o de uso da terra com propósitos florestais e para atividades agrícolas, a uma determinada taxa de desconto, a metodologia do Valor Presente 
trará como melhor opção a primeira e, variando essa taxa, a melhor escolha do investidor será a segunda alternativa. Logo, pode-se esperar que em algum momento haverá uma taxa que igualará as duas opções, em termos de valor presente dos fluxos de caixa. Essa situação é abordada por Fisher (1907) com um novo estudo de caso hipotético, cujos fluxos estão representados nas colunas A e B da Tabela 3.

\section{Tabela 3 - Fluxos de caixa das possibilidades de uso da terra e a diferença anual entre elas}

\begin{tabular}{c|c|c|c}
\hline Período & Propósitos Florestais (A) & Atividade Agrícola (B) & $\begin{array}{c}\text { Diferença } \\
(\mathbf{A}-\mathbf{B})\end{array}$ \\
\hline Ano 1 & $\$ 0$ & $\$ 100$ & $-\$ 100$ \\
\hline Ano 2 & $\$ 210$ & $\$ 100$ & $\$ 110$ \\
\hline Ano 3 & $\$ 100$ & $\$ 100$ & $\$ 0$ \\
\hline Ano 4 & $\$ 100$ & $\$ 100$ & $\$ 0$ \\
\hline Ano 5 & $\$ 100$ & $\$ 100$ & $\$ 0$ \\
\hline $\mathbf{\vdots}$ & $\vdots$ & $\vdots$ & $\vdots$ \\
\hline Ano n & $\$ 100$ & $\$ 100$ & $\$ 0$ \\
\hline
\end{tabular}

Fonte: Adaptado de Fisher (1907).

Pode-se verificar que, nesse caso, a taxa de desconto que iguala o valor presente das duas possibilidades de investimento é de $10 \%$ a.a. Se os dois fluxos de caixa forem descontados a uma taxa de $9 \%$ a.a. a alternativa de uso da terra para propósitos florestais terá um valor presente de $\$ 1112$, enquanto que o da segunda alternativa será de $\$ 1111$. Uma taxa de desconto de $11 \%$ a.a. tornará esses valores iguais a $\$ 908$ e $\$ 909$, respectivamente. Assim, para descobrir a taxa que iguala o valor presente dos dois investimentos deve-se levar em consideração aquela que torna nulo o valor presente do "fluxo das diferenças", que neste caso é 10\% a.a. Esta taxa foi denominada Taxa de Retorno do Sacrifício. O termo "sacrifício" foi utilizado para caracterizar a perda relativa de um dos fluxos de caixa, considerando sua substituição por outro e o termo "retorno" para caracterizar o ganho oriundo dessa mesma substituição. Concluindo sua metodologia, Fisher (1907) definiu que, após calcular a taxa de retorno do sacrifício, deve-se compará-la com a taxa de juros atual de mercado, à qual o investidor pode aplicar seu patrimônio; sendo a taxa de mercado menor, a opção pela segunda alternativa é a mais viável. 
É evidente que a teoria desenvolvida por Fisher (1907) representou um grande salto na forma com que as alternativas de investimentos poderiam ser analisadas, aproximando-se, inclusive, da metodologia atual da TIR. Porém, havia ainda uma diferença conceitual a ser considerada, levando-se em conta a parte em que Fisher (1907) sugeriu que seja tomada a diferença entre os dois fluxos para análise.

Essa teoria avançou quando Boulding (1935) criou um método para encontrar o que chamou de Taxa Interna de Retorno. A metodologia formulada por ele é análoga a definição atual da TIR, entretanto, não foi diretamente relacionada com o estudo da rentabilidade de um projeto em si, mas de toda a geração de caixa de uma empresa, considerando inclusive o seu valor atual.

De maneira análoga à definição de Boulding (1935) e fortemente influenciado pelas conclusões do trabalho de Fisher (1907) (Kregel, 1988), Keynes (1936) definiu a Eficiência Marginal de Capital, a taxa de desconto que faz com que o valor presente das anuidades geradas pelo investimento de capital (fluxos de caixa positivos) se iguale ao preço de oferta (também chamado de custo de reposição ou custos de produção).

Em 1937, Paul Anthony Samuelson pontuou a equivalência das teorias de Boulding (1935) e Keynes (1936), além de relacioná-las com a sua própria, intitulada Taxa Interna de Juros. Desta vez foi enfatizada a possibilidade dos múltiplos resultados. Assim, Samuelson concluiu que, embora em condições ideais o método apresente uma boa indicação da rentabilidade, ele não deveria ser o único foco de maximização para um bom investidor (Samuelson apud Parker, 1968).

A partir desse momento, principalmente próximo dos anos 50, o tema se popularizou e esteve presente em publicações de diversos autores. Desta vez o foco não era mais o desenvolvimento da ferramenta e sim a aplicabilidade da metodologia, as possíveis falhas e as características dos fluxos de caixa que os tornariam aptos para o uso do método da TIR.

Então, Lorie e Savage (1955) abordaram de uma maneira bastante abrangente as dificuldades encontradas pelos executivos diante da necessidade de se escolher entre investimentos de capital considerados mutuamente exclusivos. Com esse termo, os autores se referiram a investimentos, cuja escolha por um implica na rejeição pelo outro. O primeiro ponto considerado é de como conseguir 
utilizar o custo de capital dos acionistas da empresa para poder decidir pela aceitação ou rejeição de um projeto.

Segundo Lorie e Savage (1955), a determinação do custo de capital de uma empresa é a etapa mais complexa, pois o custo de capital dos investidores é influenciado por muitas variáveis de difícil determinação. Entretanto, chegar a esse valor não foi o foco do referido trabalho. Tendo em mãos o valor do custo de capital, para que um projeto de investimento possa ser considerado aceitável, devese aplicar a metodologia do Valor Presente Líquido (VPL) ao fluxo de caixa esperado do investimento e, então, analisar o valor obtido. Caso seja maior ou igual a zero, o mesmo está de acordo com os padrões de aceitação, levando em consideração o custo de capital da empresa. Caso seja negativo, o resultado mostra que, embora possa até gerar algum retorno, o projeto não apresenta resultados suficientes para satisfazer às exigências mínimas dos investidores.

Outro ponto discutido por Lorie e Savage (1955) foi a equivalência do resultado obtido aplicando-se o método do VPL e da TIR em um mesmo estudo de viabilidade. Para o caso citado anteriormente, quando se sabe qual é o custo do capital da empresa, os autores afirmam que o critério de aceitação ou rejeição do projeto utilizando esse método seria a comparação entre o custo de capital e a TIR do seu fluxo de caixa projetado. Caso a TIR seja maior que o custo de capital, previamente estabelecido, o projeto apresenta uma rentabilidade satisfatória, sendo que a aplicação do método do VPL tem como resultado um valor positivo para a criação de valor, considerando a rentabilidade mínima estabelecida pelo investidor.

Entretanto, a contribuição mais relevante do trabalho de Lorie e Savage (1955) foi um estudo do comportamento dessa métrica de viabilidade. Foram definidas duas formas típicas de comportamento do gráfico da Taxa de Juros versus Valor Presente (Figuras 1 e 2), cuja curva representa o valor presente de um investimento a diferentes taxas de juros, o ponto "a" representa o custo de capital da empresa, os pontos "b" e "c" representam taxas internas de retorno do investimento (conforme definição: a taxa de desconto para qual o VPL é nulo) e a linha "a'a" representa o valor presente do investimento, quando descontado à taxa que representa o custo de capital do investidor.

Lorie e Savage (1955) observaram que, para comportamentos similares ao da curva da FIGURA 1, caso o VPL calculado utilizando a taxa que representa o Custo de Capital seja maior ou igual a zero, inevitavelmente a TIR do fluxo será 
maior ou igual ao Custo de Capital do investidor. Dessa forma pode-se concluir que as duas metodologias trazem o mesmo resultado, sendo complementares.

Figura 1 - Comportamento da curva do valor presente de um fluxo de caixa

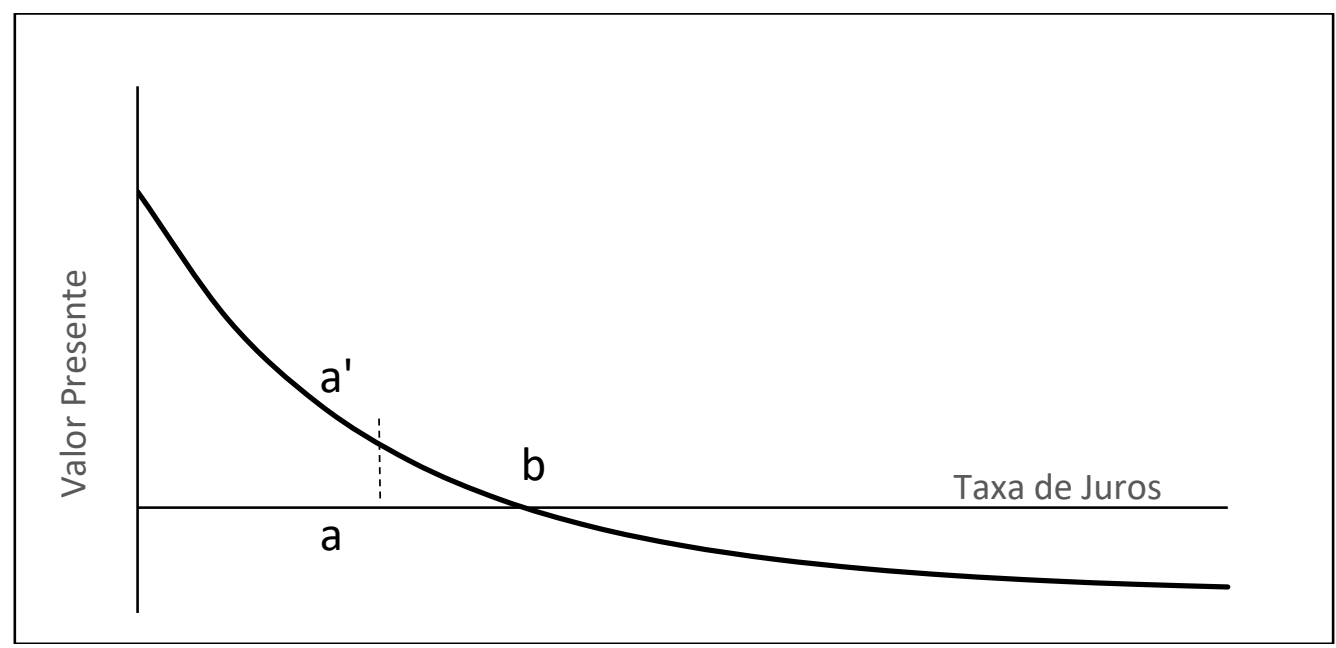

Fonte: Adaptado de Lorie e Savage (1955).

Seguindo o raciocínio, Lorie e Savage (1955) verificaram que nem sempre a função apresentará um comportamento decrescente. Alguns fluxos de caixa, especificamente os que apresentam saídas de caixa no início, entradas intermediárias e terminam com fluxos negativos, acabam tendo o comportamento descrito pela Figura 2, com duas intersecções no eixo das abscissas (duas TIR's).

Figura 2 - Comportamento da curva do valor presente de um fluxo de caixa

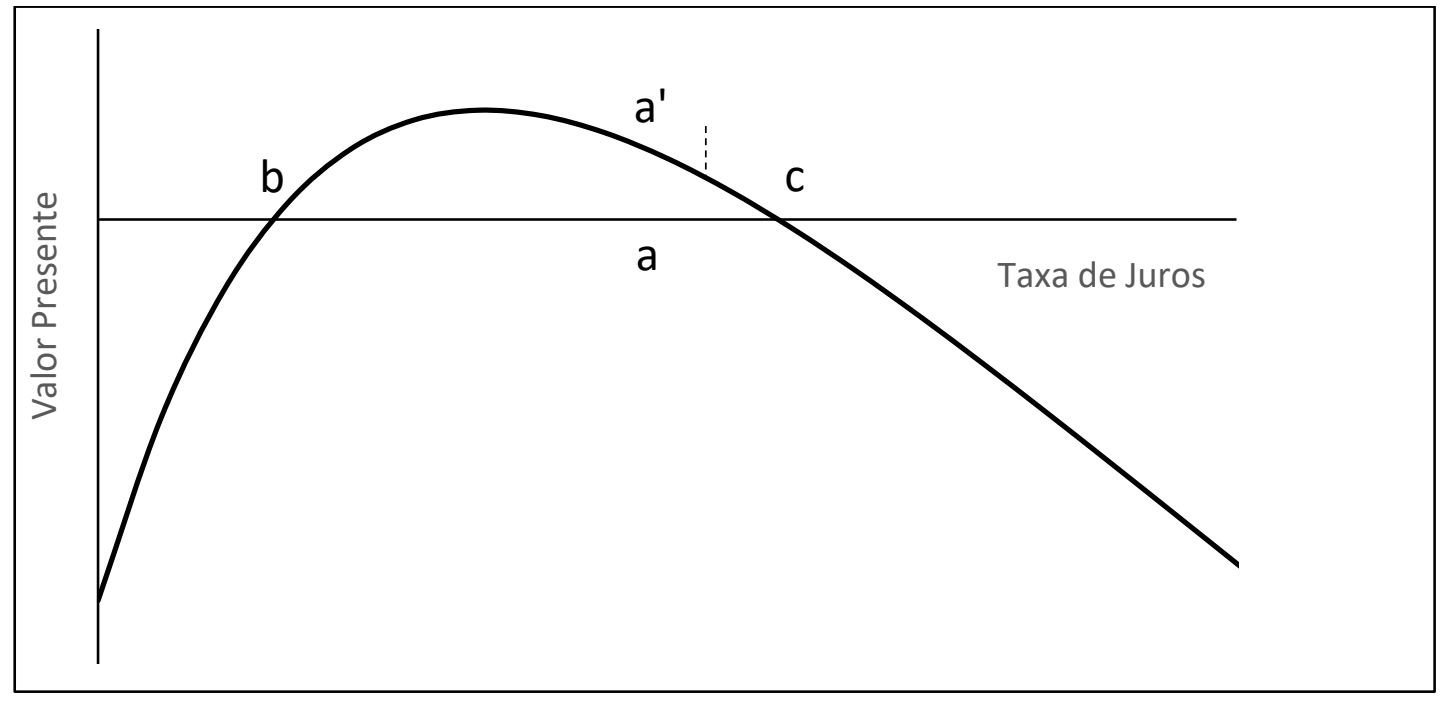

Fonte: adaptado de Lorie e Savage (1955). 
Até esse momento, o tema não fora tratado com uma abordagem gráfica, que foi o diferencial do estudo dos autores, embora o problema das múltiplas taxas internas de retorno já fosse mencionado por Boulding (1935). Lorie e Savage (1955) concluem o estudo dos gráficos fazendo uma análise do impacto do incremento da taxa de juros no fluxo com o comportamento demonstrado na Figura 2:

\begin{abstract}
Partindo da origem do gráfico, considerando hipoteticamente que o custo de capital da empresa está perto de zero, o valor presente do fluxo de caixa será a soma algébrica de todos os fluxos de caixa, logo, poderá ser negativo, caso esta soma seja negativa. Com o acréscimo da taxa que representa o custo de capital, os valores presentes dos últimos períodos do fluxo de caixa tendem a diminuir sua importância perante os valores dos períodos iniciais, e isso pode fazer com que o valor presente do fluxo total se torne positivo. Se ainda assim continuar considerando um acréscimo no custo de capital, os fluxos de caixa futuros em sua totalidade (positivos ou não) tendem a diminuir sua importância perante o todo, fazendo com que o valor presente do fluxo se aproxime, no limite, à saída de caixa inicial. (Lorie; Savage, 1955, p. 237-238, tradução nossa)
\end{abstract}

Assim, segundo Lorie e Savage (1955), nesses casos o critério para definir a aceitabilidade do investimento proposto, baseado na Taxa Interna de Retorno, é ambíguo e anômalo, além de que esse fator acaba com a clareza e acurácia do princípio de que a TIR é complementar ao método do VPL, pois nessas circunstâncias a metodologia gera mais de um resultado.

Então, em 1956, Ezra Solomon apresentou um estudo focado no que definiu como um problema lógico e aritmético: prover a quem gerencia uma empresa um conjunto de padrões adequados, com os quais poderia selecionar projetos para a execução, de maneira a maximizar os benefícios econômicos de longo prazo para os investidores. A primeira abordagem do autor defendeu o uso da TIR, definindo que, caso o seu valor seja maior que o custo de capital da companhia, o projeto deveria ser aceito. Em seguida, defendeu o uso do método do VPL utilizando como taxa de desconto o custo de capital da empresa, definindo que, caso o valor presente das entradas de caixa seja maior que os valores das saídas, o projeto deveria ser aceito.

Ainda, segundo Solomon (1956), essas duas metodologias devem trazer os mesmos resultados para questões de aceitação ou rejeição de projetos. Entretanto, em problemas um tanto quanto mais complexos, a aplicação desses dois critérios acaba gerando resultados ambíguos e contraditórios que devem ser explorados. A título de análise, na Tabela 4, apresentam-se os dois fluxos de caixa hipotéticos sugeridos pelo autor. 
Tabela 2 - Fluxos de caixa de dois projetos hipotéticos

\begin{tabular}{c|c|c|c|c|c}
\hline Descrição & Ano 0 & Ano 1 & Ano 2 & Ano 3 & Ano 4 \\
\hline Projeto X & $(\$ 100,0)$ & $\$ 120,0$ & $\$ 0,0$ & $\$ 0,0$ & $\$ 0,0$ \\
\hline Projeto Y & $(\$ 100,0)$ & $\$ 0,0$ & $\$ 0,0$ & $\$ 0,0$ & $\$ 174,9$ \\
\hline
\end{tabular}

Fonte: Solomon (1956).

Segundo Solomon (1956), ao se calcular a TIR do Projeto X, obtém-se como resultado $20 \%$ a.a., enquanto que para o projeto $\mathrm{Y}$ o mesmo cálculo gera uma TIR de $15 \%$ a.a. Logo, utilizando essa metodologia, o projeto $\mathrm{X}$ seria selecionado, por ter um valor maior de rentabilidade. Entretanto, usando-se o Método do Valor Presente Líquido, a um custo de capital de $10 \%$ a.a., obtém-se para o projeto $\mathrm{X}$ o valor de $\$ 9,09$, enquanto que para o projeto $\mathrm{Y}$ o resultado é de $\$ 19,46$, implicando na escolha do projeto Y. Com isso, pode-se concluir que existe uma inconsistência entre os métodos.

Em defesa do uso dos métodos, Solomon (1956) concluiu que, entre os anos 1 e 4, as duas metodologias, se usadas sem nenhum desvio em relação a sua definição, fazem considerações implícitas diferentes. Usando a TIR, considera-se que os $\$ 120$ obtidos do projeto $X$, no ano 1, podem ser reinvestidos entre os anos 1 e 4 a uma taxa lucrativa o suficiente para acumular mais que $\$ 174,9$ no ano 4. Já a abordagem do valor presente assume que os fundos obtidos de ambos os projetos podem ser reinvestidos a uma taxa igual ao custo de capital. Portanto, para Solomon (1956), o aparente conflito entre as duas abordagens tem origem nas diferentes definições assumidas por cada uma delas sobre o futuro e que, caso seja adotada uma mesma consideração, ambas trarão o mesmo resultado, como é de se esperar.

Solomon (1956) sugere, ainda, como correção necessária para a inconsistência descrita anteriormente que, para o projeto $X$, entre os anos 1 e 4, seja considerado o investimento das entradas de caixa a uma taxa média de $12 \%$ a.a., por exemplo, chegando ao que o autor definiu como "valor terminal" de \$168,47. Como o projeto Y não apresenta nenhuma entrada de caixa intermediária, o seu "valor terminal" será exatamente o fluxo de caixa no ano 4, \$174,9. Então, o fluxo de caixa usado para a comparação seria aquele que considera o "valor terminal" de cada projeto, conforme Tabela 3. 
Tabela 3 - Fluxos de caixa de valores terminais de dois projetos

\begin{tabular}{c|c|c|c|c|c}
\hline \multirow{2}{*}{ Projeto } & \multicolumn{5}{|c}{ Ano } \\
\cline { 2 - 6 } & $\mathbf{0}$ & $\mathbf{1}$ & $\mathbf{2}$ & $\mathbf{3}$ & $\mathbf{4}$ \\
\hline $\mathrm{X}$ & $(\$ 100,0)$ & $\$ 0,0$ & $\$ 0,0$ & $\$ 0,0$ & $\$ 168,6$ \\
\hline $\mathrm{Y}$ & $(\$ 100,0)$ & $\$ 0,0$ & $\$ 0,0$ & $\$ 0,0$ & $\$ 174,9$ \\
\hline
\end{tabular}

Fonte: adaptado de Solomon (1956).

Desta forma, ao se calcular a TIR para cada proposta de investimento, teremos o valor de $13,9 \%$ para o projeto $\mathrm{X}$ e $15,0 \%$ para o projeto Y. Utilizando o Método do Valor Presente, segundo Solomon (1956), deve-se ter o cuidado de descontar os fluxos a taxas adequadas, de modo que o Valor Presente do projeto $\mathrm{X}$ seria o seu valor terminal descontado a $12 \%$ a.a. (taxa de investimento) até o ano 1 e, então, o montante descontado a $10 \%$ a.a. (custo de capital) até o ano 0 , tendo como resultado o valor de $\$ 109,09$. Usando a mesma sistemática para o projeto $\mathrm{Y}$, chega-se ao resultado de $\$ 113,17$. Logo, após o ajuste proposto, a inconsistência no resultado gerado pelas duas metodologias é eliminada e ambas as técnicas geram o mesmo resultado.

Contudo, Solomon (1956) concluiu seu trabalho com uma análise do tema levantado por Lorie e Savage (1955), acerca da multiplicidade de resultados que o método da Taxa Interna de Retorno pode acarretar. Para isso, considerou o seguinte problema, um negócio de extração de petróleo: uma proposta de substituição de uma bomba de menor por outra de maior dimensão, que irá extrair a matéria-prima com maior rapidez. Entretanto, com a bomba atual (Bomba A) o investidor tem como certo um fluxo de caixa de $\$ 10.000$ no ano 1 e mais $\$ 10.000$ no ano 2. Optando por substituir o equipamento em uso pela Bomba B, terá um fluxo líquido no ano 0 de $\$ 1.600$, no ano 1 uma entrada de $\$ 20.000$ e, no ano 2, nenhum fluxo de caixa seria gerado. Desta forma, chega-se ao fluxo de caixa incremental, calculado como sendo a diferença entre os fluxos de caixa anuais das duas opções de equipamentos, no ano 0 o valor de $-\$ 1.600$, no ano 1 de $\$ 10.000$ e no ano 3 de $-\$ 10.000$.

Ao se calcular a TIR do fluxo gerado, observa-se que existem dois possíveis resultados, $25 \%$ a.a. e $400 \%$ a.a., caracterizando exatamente o que foi previsto no trabalho de Lorie e Savage (1955), como um fluxo de caixa que gera uma curva do Valor Presente versus Taxa de Desconto cruzando o eixo das abscissas em dois pontos, conforme Figura 3. Solomon (1956) demonstrou, então, que embora as 
duas taxas encontradas façam com que o valor presente do fluxo de caixa seja igual a zero, nenhuma pode ser considerada como a rentabilidade do investimento.

Figura 3 - VPL do fluxo de caixa incremental

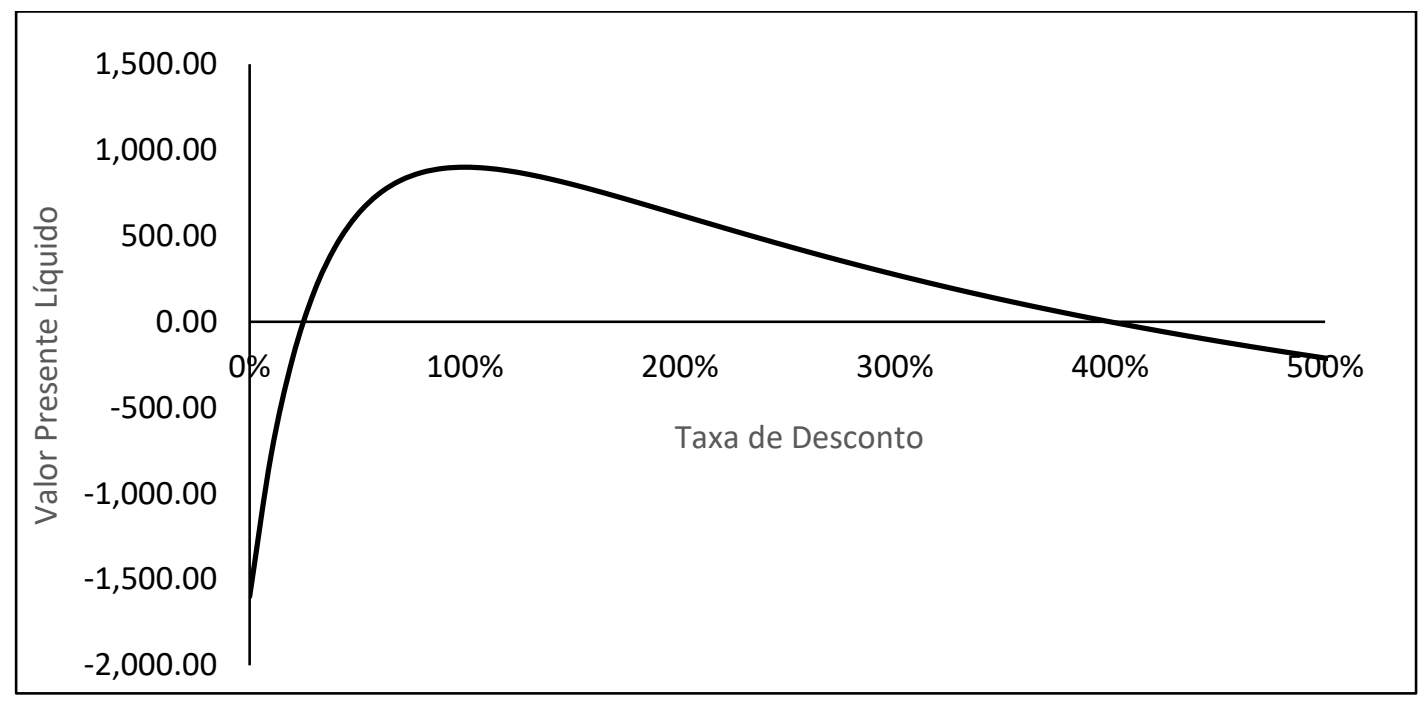

Fonte: Solomon (1956).

Para embasar sua afirmação, Solomon (1956) inicia uma análise variando o fluxo no ano 0 (cujo valor inicial é negativo, representando o desembolso com a compra da nova bomba): ao se zerar o custo inicial, usando o método da TIR como em sua definição, tem-se uma rentabilidade de $0 \%$ a.a. Se o custo inicial for aumentado para $\$ 827$, o método indica uma rentabilidade de $10 \%$ a.a. Ao elevar o custo para $\$ 1600$, por exemplo, a taxa de retorno indicada pelo método é de $25 \%$ a.a.

Logo, ao se considerar acréscimos progressivos no custo do equipamento, verifica-se que o método traz como solução rentabilidades cada vez maiores. Esse fato, segundo Solomon (1956), é claramente o indício de um erro na metodologia, pois não faz sentido que a consideração de aumento do custo inicial, sem variar nenhum outro parâmetro de receita, gere acréscimos na rentabilidade do projeto.

Para finalizar, Solomon (1956) sugeriu que, usando ainda o exemplo da substituição das bombas, a geração de valor que os $\$ 10.000$ antecipados para o ano 1 terão até o término do ano 2 deve ser foco de análise, visto que essa é a efetiva mudança no fluxo de caixa gerada pela substituição dos equipamentos. Exemplificando, caso o investidor possa aplicar os $\$ 10.000$ (excedentes em relação ao fluxo de caixa original) gerados no ano 1 em algum negócio que forneça um rendimento de $23 \%$ a.a., um ano depois, terá uma geração de valor da ordem de 
$\$ 2.300$. Ou seja, se o investidor gastou $\$ 1.600$ em um equipamento no ano 0, ele irá terminar o ano 2 tendo $\$ 2.300$ a mais do que se não trocasse de bomba e defende que é desse fluxo que deve ser extraída a taxa de retorno do investimento, que resultaria em $20 \%$ a.a. no caso estudado.

Percebe-se, nesse momento, que o foco principal dos estudos a respeito do tema era determinar suas limitações e, dependendo do caso, até mesmo a viabilidade do seu uso. Entretanto, com sua análise e considerando o possível investimento de fluxos de caixa, Solomon (1956) deu margem para a definição do que posteriormente seria chamada de Taxa Interna de Retorno Modificada.

Após os trabalhos já mencionados, Renshaw (1957) fez a sua contribuição, complementando os trabalhos de Solomon (1956) e Lorie e Savage (1955), visando esclarecer e aprofundar-se em alguns pontos elencados por seus predecessores. No que tange à inconsistência de resultados gerada pela aplicação do método do Valor Presente e da TIR, Renshaw (1957) enfatizou que esse fato ocorre necessariamente (mas não exclusivamente) quando os fluxos de caixa comparados diferem em relação ao tempo. Segundo Renshaw (1957), esse comportamento acontece por conta de mudanças na taxa de desconto aplicada que impactam em alterações mais significantes nos fluxos de caixa, que ocorrem em um tempo mais distante da data inicial, de maneira que, ao se comparar fluxos com durações distintas, o mais longo seria mais impactado.

Renshaw (1957) também mencionou as considerações de reinvestimento implícitas nos métodos do VP e da TIR levantadas por Solomon (1956), bem como sua sugestão para contornar o problema. Para Renshaw (1957), trata-se do uso de uma consideração explícita de retorno esperado devido a reinvestimentos. Desta forma, seria possível reduzir os fluxos de caixa para o valor presente ou, então, compô-los para valores terminais, como determinado no trabalho de Solomon (1956). Entretanto, a taxa de retorno obtida ao fim desse processo é uma taxa média, que engloba o retorno do projeto e do reinvestimento, não gerando um resultado exclusivo do projeto em questão.

No que tange às múltiplas taxas de retorno de um fluxo de caixa, Renshaw (1957) observou que o método utilizado por Solomon (1956) trata do que anteriormente fora definido por Fisher (1907) como a taxa de retorno do sacrifício, por estar considerando, para fins de cálculo de retorno, o fluxo de caixa oriundo da diferença entre dois outros, cuja aceitação de um implica na rejeição do outro. 
Renshaw (1957) encerrou sua contribuição esclarecendo o comportamento do VP dos dois fluxos de caixa elaborados por Solomon (1956), conforme TABELA 6.

Tabela 6 - Comportamento do VPL dos fluxos de caixa elaborados por Solomon (1956)

\begin{tabular}{c|r|r|r}
\hline \multirow{2}{*}{$\begin{array}{c}\text { Taxa de } \\
\text { Juros }\end{array}$} & \multicolumn{3}{|c}{ Valor Presente dos Fluxos de Caixa no Ano 0 } \\
\cline { 2 - 4 } & Alternativa A & Alternativa B & \multicolumn{1}{c}{ Fluxo Incremental } \\
\hline $0 \%$ & 18400,0 & 20000,0 & $-1600,0$ \\
\hline $20 \%$ & 15066,7 & 15277,8 & $-211,1$ \\
\hline $25 \%$ & 14400,0 & 14400,0 & 0,0 \\
\hline $50 \%$ & 11733,3 & 11111,1 & 622,2 \\
\hline $100 \%$ & 8400,0 & 7500,0 & 900,0 \\
\hline $200 \%$ & 5066,7 & 4444,4 & 622,2 \\
\hline $300 \%$ & 3400,0 & 3125,0 & 275,0 \\
\hline $400 \%$ & 2400,0 & 2400,0 & 0,0 \\
\hline $500 \%$ & 1733,3 & 1944,4 & $-211,1$ \\
\hline $1150 \%$ & 0,0 & 864,0 & $-864,0$ \\
\hline infinita & $-1600,0$ & 0,0 & $-1600,0$ \\
\hline
\end{tabular}

Fonte: adaptado de Renshaw (1957).

Além disso, Renshaw (1957) demonstrou graficamente (FIGURA 4), o comportamento das curvas, podendo-se verificar os pontos onde o valor presente do fluxo de caixa incremental é nulo. 
Figura 4 - Taxa de juros $x$ valor presente dos fluxos de caixa

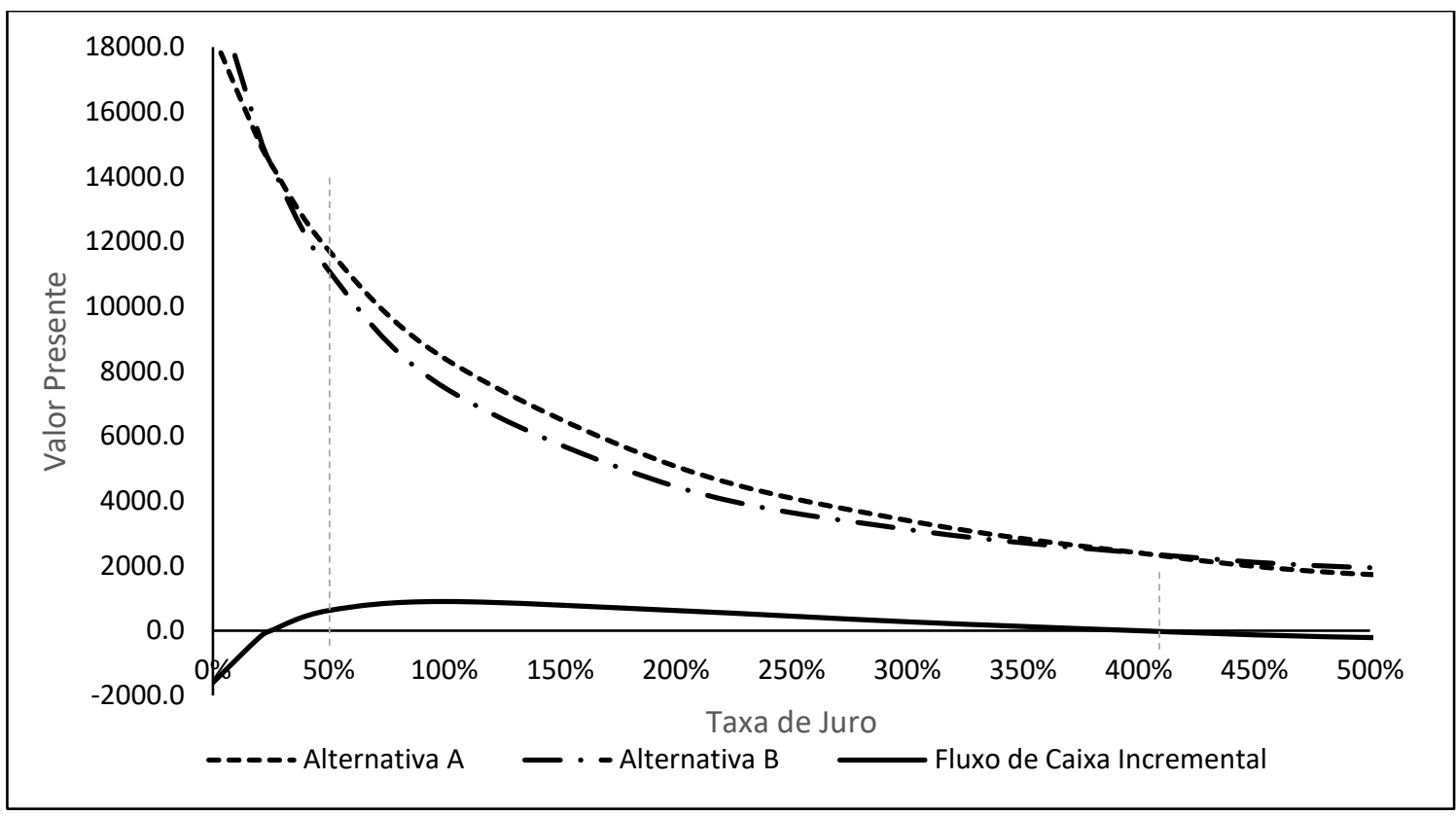

Fonte: adaptado de Renshaw (1957).

Estando feitas todas as principais definições e pontuações das críticas à aplicação do método da TIR pelos trabalhos anteriores, um grande salto no desenvolvimento do entendimento acerca das peculiaridades e aparentes inconsistências da metodologia ocorreu com a publicação do trabalho de Dudley Junior (1972). O autor fez uma abordagem prática completa, usando um exemplo de escolha entre 4 projetos (denominados A, B, C e D) com investimentos iniciais idênticos, entretanto, com entradas de caixa distintas em relação aos seus valores e seus prazos (Tabela 7).

Tabela 7 - Fluxos de caixa com investimentos idênticos e retornos variáveis no tempo e em valores

\begin{tabular}{l|c|r|r|r|r}
\hline \multirow{2}{*}{ Descrição } & \multirow{2}{*}{ Período } & \multicolumn{5}{c}{ Projeto } \\
\cline { 3 - 6 } & & \multicolumn{1}{c|}{$\mathbf{A}$} & \multicolumn{1}{c}{ B } & \multicolumn{1}{c}{$\mathbf{C}$} & \multicolumn{1}{c}{ D } \\
\hline Investimento Inicial & 0 & $-\$ 35.282$ & $-\$ 35.282$ & $-\$ 35.282$ & $-\$ 35.282$ \\
\hline \multirow{3}{*}{ Fluxo de Caixa } & 1 & 20.000 & 16.691 & 10.949 & 5.000 \\
\cline { 2 - 7 } & 2 & 15.000 & 16.691 & 10.949 & 10.000 \\
\cline { 2 - 6 } & 3 & 10.000 & 16.691 & 10.949 & 15.000 \\
\cline { 2 - 6 } & 4 & 5.000 & 0 & 10.949 & 25.514 \\
\cline { 2 - 6 } & 5 & 0 & 0 & 10.949 & 0 \\
\hline \multirow{2}{*}{ Recebimentos } & - & $\$ 50.000$ & $\$ 50.073$ & $\$ 54.745$ & $\$ 55.514$ \\
\hline
\end{tabular}

Fonte: adaptado de Dudley Junior (1972). 
Ao se calcular o VPL e a TIR dos investimentos apresentados na TABELA 8, nota-se que foram rigorosamente selecionados por Dudley Junior (1972), de modo que o ranking gerado pelas duas métricas é bem distinto.

Tabela 8 - Métricas de avaliação dos fluxos de caixa

\begin{tabular}{l|r|r|r|r}
\multicolumn{1}{c|}{ Projetos } & \multicolumn{1}{c|}{ A } & \multicolumn{1}{c|}{ B } & \multicolumn{1}{c|}{ C } & \multicolumn{1}{c}{ D } \\
\hline Investimento Inicial & $-\$ 35.282$ & $-\$ 35.282$ & $-\$ 35.282$ & $-\$ 35.282$ \\
\hline VP a 7\% a.a. & 43.771 & 43.802 & 44.893 & 45.116 \\
\hline VPL & 8.489 & 8.520 & 9.611 & 9.834 \\
\hline $\begin{array}{l}\text { Índice de Rentabilidade } \\
\text { (VP/Inv. Inicial) }\end{array}$ & 1,241 & 1,241 & 1,272 & 1,279 \\
\hline TIR (\%) & $20,00 \%$ & $19,78 \%$ & $16,69 \%$ & $16,18 \%$ \\
\hline
\end{tabular}

Fonte: Dudley Junior (1972).

Embasado nos resultados expostos na TABELA 8, Dudley Jr (1972) observou que, conforme mencionado por Solomon (1956), não é possível avaliar diversos projetos mutuamente exclusivos considerando apenas o fluxo de caixa individual de cada um, pois eles podem ter durações distintas. $\mathrm{O}$ autor defendeu ainda que é necessário considerar os fluxos com horizonte comum de planejamento, no caso 5 anos, chegando-se aos valores terminais - em função da taxa do reinvestimento realizado (Tabela 9).

Tabela 9 - Valores terminais em um horizonte de 5 anos

\begin{tabular}{c|c|c|c|c|c}
\hline Descrição & \multicolumn{5}{c}{ Valores Terminais } \\
\hline Projeto & & $\mathbf{A}$ & $\mathbf{B}$ & $\mathbf{C}$ & \multicolumn{1}{c}{$\mathbf{D}$} \\
\hline $\begin{array}{c}\text { Índice de Rentabilidade } \\
\text { (VP/Inv. Inicial) }\end{array}$ & 1,241 & 1,241 & 1,272 & 1,279 \\
\hline TIR (\%) & & $20,00 \%$ & $19,78 \%$ & $16,69 \%$ & $16,18 \%$ \\
\hline \multirow{4}{*}{ Taxa de Reinvestimento (\%): } & $0 \%$ & $\$ 50.000$ & $\$ 50.073$ & $\$ 54.745$ & $\$ 55.514$ \\
\cline { 2 - 7 } & $5 \%$ & 57.690 & 58.017 & 60.503 & 60.980 \\
\cline { 2 - 7 } & $7 \%$ & 61.391 & 61.435 & 62.965 & 63.278 \\
\cline { 2 - 7 } & $10 \%$ & 66.845 & 66.848 & 66.843 & 66.845 \\
\cline { 2 - 6 } & $15 \%$ & 76.765 & 76.646 & 73.818 & 73.126 \\
\cline { 2 - 6 } & $20 \%$ & 87.800 & 87.494 & 81.483 & 79.867 \\
\hline
\end{tabular}

Fonte: Dudley Junior (1972).

Avaliando o Tabela 9, observa-se que a uma taxa de reinvestimento de $10 \%$ a.a. os projetos terão praticamente o mesmo valor terminal e que esse ponto separa 
o comportamento do ranking, de forma que a consideração de taxas maiores implica em um valor terminal maior para o Projeto A, e tem-se como resultado a mesma classificação de projetos gerada pelo método da TIR. Por outro lado, a consideração de taxas menores faz acontecer o oposto (Dudley Junior, 1972). Desta maneira, Dudley Junior (1972) faz a verificação da teoria anteriormente definida por Fisher (1907), sendo que 10\% a.a. é a Taxa de Retorno do Sacrifício para o conjunto de projetos em questão, entretanto, encontra uma relação relevante acerca da Taxa de Retorno de Fisher e a TIR, inédita até então.

Ao mesmo tempo em que se faziam estudos sobre a aplicação dos métodos, os mesmos estavam sendo amplamente difundidos entre as grandes empresas. Levando em consideração o mercado americano, em 1972, cerca de $57 \%$ das médias e grandes empresas utilizavam métodos de fluxo de caixa descontados (TIR ou VPL) para avaliar seus investimentos (Klammer, 1972). Seis anos depois, em 1978, pesquisas revelam que os métodos de fluxo de caixa descontados já eram utilizados por cerca de $86 \%$ das empresas americanas (Schall et al., 1978).

Em se tratando diretamente do uso do método da Taxa Interna de Retorno, Rapp (1980) trouxe um resumo de dados publicados entre os anos 1967 e 1978, elencando o percentual, dentro do conjunto de empresas pesquisado, de utilização do método da TIR como ferramenta de decisão para realizar investimentos (Tabela 10).

Tabela 10 - Utilização do método da TIR entre 1967 e 1978

\begin{tabular}{c|c}
\hline País & Empresas que utilizam o método da TIR (\%) \\
\hline Estados Unidos & 71 \\
Inglaterra & 76 \\
Finlândia & 77,7 \\
Suécia & 54 \\
\hline
\end{tabular}

Fonte: adaptado de Rapp (1980).

Em meio à popularização dos métodos e dos desdobramentos já mencionados, gradativamente mais estudos acerca da incompatibilidade de resultados entre os métodos da TIR e do VPL foram desenvolvidos. Lin (1976) publicou uma nova metodologia visando suprir as inconsistências debatidas até 
então, a qual foi denominada LRR (Taxa de Retorno Modificada de Lin). O método consiste em uma consideração explícita de reinvestimento, de modo que todas as entradas de caixa são carregadas para o último período do fluxo, a uma taxa de investimento, compondo o valor terminal das entradas de caixa (VTEC) conceito similar ao definido por Solomon (1956). Seguindo a metodologia, todas as saídas de caixa deveriam ser trazidas para o valor presente, utilizando o custo do capital envolvido, resultando na Base de Investimento (BI), conforme Equação (1).

$$
L R R=\left(-\frac{V T E C}{B I}\right)^{\frac{1}{n}}-1
$$

onde n é o número de períodos considerados (SHULL, 1993).

Nota-se que a metodologia utiliza conceitos atuais do cálculo da TIRM, no que diz respeito ao agrupamento de saídas de caixa e de entradas de caixa, bem como de sua movimentação para o início e o horizonte de projeto, respectivamente, levando-se em conta o valor do dinheiro no tempo.

Uma abordagem diferente das anteriores foi tratada por Rapp (1980). Visando resumir todos os pontos já elencados na literatura até então, e aplicar conceitos tentando orientar as discussões, Rapp (1980) tratou do tema do uso da TIR com base nas teorias de cálculo integral. Desta forma, define-se a TIR para um projeto simples com um investimento inicial e posteriores receitas como o valor de " $\mathrm{x}$ " capaz de tornar verdadeira a igualdade indicada na EQUAÇÃO (2).

$$
\int_{0}^{T} Q(t) \times e^{-x t} d t+S(T) \times e^{-x T}=I
$$

onde T é o número de períodos de duração do fluxo de caixa, Q(t) é o fluxo de caixa de cada período $\mathrm{t}, \mathrm{e}^{-\mathrm{xt}}$ é o fator de desconto variável para cada período $\mathrm{t}, \mathrm{S}(\mathrm{T})$ é o valor residual do projeto no período T, quando for aplicável e I é o investimento inicial no projeto.

Rapp (1980) reafirma que a Equação (2) da forma disposta pode possuir nenhuma, uma ou várias raízes. Seguindo uma análise de possíveis múltiplos resultados, pontua-se os seguintes fatores: 
1) se as relações $\mathrm{Q}(\mathrm{t}) \geq 0$ e $\mathrm{I} \geq 0$ forem verdadeiras para todos os pontos " $t$ " dentro do domínio da função, então, só existe um valor de " $\mathrm{x}$ " capaz de satisfazer a equação;

2) o número de raízes da equação não excede o número de inversões de sinal no fluxo de caixa.

3) existem fluxos de caixa que possuem apenas uma TIR, mesmo possuindo duas inversões de sinal.

Aprofundando sua análise, Rapp (1980) ainda tratou de outras especificidades do método, entretanto, destacou na sua análise que o método identifica a grande sensibilidade dos resultados da TIR, apresentando a propriedade de identificar o impacto decorrente de pequenas variações nos valores dos fluxos de caixa.

\section{As principais abordagens sobre o método da TIR no século XXI}

No início do século XXI já havia uma ampla bibliografia tanto sobre a definição quanto sobre as incompatibilidades do método da TIR (Fisher, 1907; Boulding, 1935; Keynes, 1936; Solomon, 1956; Lorie; Savage, 1955; Renshaw, 1957; Dudley Junior, 1972). Tendo uma base de dados, vários estudos de caso e uma ampla série de publicações à disposição, vários autores se dispuseram a elaborar novas metodologias visando contornar as inconsistências encontradas. Um exemplo foi Hazen (2003), que realizou uma análise muito ampla a respeito das especificidades muitas vezes mencionadas, mas pouco exploradas até então, no contexto dos possíveis resultados múltiplos ou da não existência de um resultado, utilizando-se o método da TIR, como anteriormente mencionado por Rapp (1980), Solomon (1956), Lorie e Savage (1955), Boulding (1935), entre outros.

Hazen (2003), na contramão da grande maioria dos autores, estudou uma possível aplicação do método por mais que o mesmo possua multiplicidade ou inexistência de resultados para determinado fluxo de caixa. A ideia explorada foi a de que esses resultados não podem ser considerados contraditórios, nem que as múltiplas taxas seriam inválidas. Segundo essa análise, cada resultado possui uma interpretação plausível a ser aplicada, no contexto do fluxo de caixa em que os resultados foram originados. 
Então, Hazen (2003) apresentou três exemplos numéricos de fluxos de investimentos com seus respectivos fluxos de caixa de origem, todos com o mesmo período de duração $(\mathrm{T}=3)$. A Tabela 11 apresenta um fluxo de investimentos misto (valores positivos e negativos), cuja taxa de juros é $\mathrm{k}=100 \%$; um fluxo genuíno de investimentos (somente valores positivos), cuja taxa de juros é $\mathrm{k}=50 \%$ e um fluxo genuíno de empréstimos (somente valores negativos), cuja taxa de juros é $\mathrm{k}=0 \%$.

Tabela 11 - Fluxos de investimentos

\begin{tabular}{c|c|c|c}
\hline Taxa de Juros & Período & Fluxo de caixa $(\mathbf{x})$ & $\begin{array}{c}\text { Fluxo de } \\
\text { Investimentos (c) }\end{array}$ \\
\hline \multirow{3}{*}{$\mathrm{k}=100 \%$} & 0 & -5 & 5 \\
\cline { 2 - 4 } & 1 & 30 & -20 \\
\cline { 2 - 4 } & 2 & -55 & 15 \\
\hline \multirow{3}{*}{$\mathrm{k}=50 \%$} & 3 & 30 & - \\
\cline { 2 - 4 } & 0 & -20 & 20 \\
\cline { 2 - 4 } & 1 & 10 & 20 \\
\cline { 2 - 4 } & 2 & 10 & - \\
\hline \multirow{3}{*}{$\mathrm{k}=0 \%$} & 3 & 30 & -20 \\
\cline { 2 - 4 } & 0 & 20 & -40 \\
\cline { 2 - 4 } & 1 & 10 & - \\
\hline
\end{tabular}

Fonte: Hazen (2013).

Hazen (2003) postula uma definição adicional de Taxa Interna de Retorno para um fluxo de caixa " $x$ ", como sendo uma taxa constante por período de tempo capaz de fazer com que o fluxo de investimentos "c" gere o fluxo de caixa " $x$ ". Além disso, se o fluxo de investimentos oriundo de um fluxo de caixa for genuíno (de empréstimos ou de investimentos), então a TIR do fluxo de caixa ao qual se refere será única e igual a $\mathrm{k}$.

A análise de fluxos de caixa que geram fluxos mistos de investimentos precisa, necessariamente, ser mais elaborada. De acordo com as possíveis características desses fluxos, Hazen (2003) os separa em dois grandes grupos, a saber: 
- Investimento Líquido: é a definição dada a um fluxo misto de investimentos (c) cujo valor presente a uma taxa de desconto " $\mathrm{r}$ " (necessariamente igual à taxa de mercado) é positivo.

- Empréstimo Líquido: é a definição dada a um fluxo misto de investimentos (c) cujo valor presente a uma taxa de desconto " $r$ " (necessariamente igual à taxa de mercado) é negativo.

Desta forma, define-se que fluxos de caixa que geram um fluxo misto de investimentos caracterizado como investimento líquido devem ser aceitos apenas se o valor da taxa " $k$ " for superior à taxa de mercado " $r$ " (VPL > 0). No caso em que o fluxo misto de investimentos se enquadrar na definição de empréstimo líquido, o fluxo de caixa ao qual está relacionado deverá ser aceito apenas se o valor de " $k$ " for inferior à taxa de mercado, ou seja, quando o VPL for negativo (Hazen, 2003).

A fim de verificar essa abordagem, prossegue-se o estudo com uma série de exemplos, dos quais selecionou-se o mais abrangente para ser explorado a seguir: considerando-se o fluxo de caixa de um projeto hipotético $\mathbf{x}=\left(\mathrm{x}_{0}, \mathrm{x}_{1}, \mathrm{x}_{3}, \mathrm{x}_{4}\right)=(-$ $1,6,-11,6)$, obtém-se a curva relacionando valor presente líquido e taxa de desconto apresentada no Figura 5.

Logo, pode-se observar que a aplicação do método da TIR trará como resultado os valores de $0 \%, 100 \%$ e $200 \%$, sendo os valores de taxa de desconto para os quais o VPL é nulo. Considerando as conclusões dos trabalhos já citados anteriormente, o fato de gerar múltiplos resultados seria suficiente para que o método da TIR fosse considerado inadequado para o fluxo em questão, sendo necessário explorar outras maneiras de avaliar o fluxo de caixa.

Figura 5 - Exemplo hipotético de solução de múltiplas TIR's:

VPL $x$ taxa de desconto

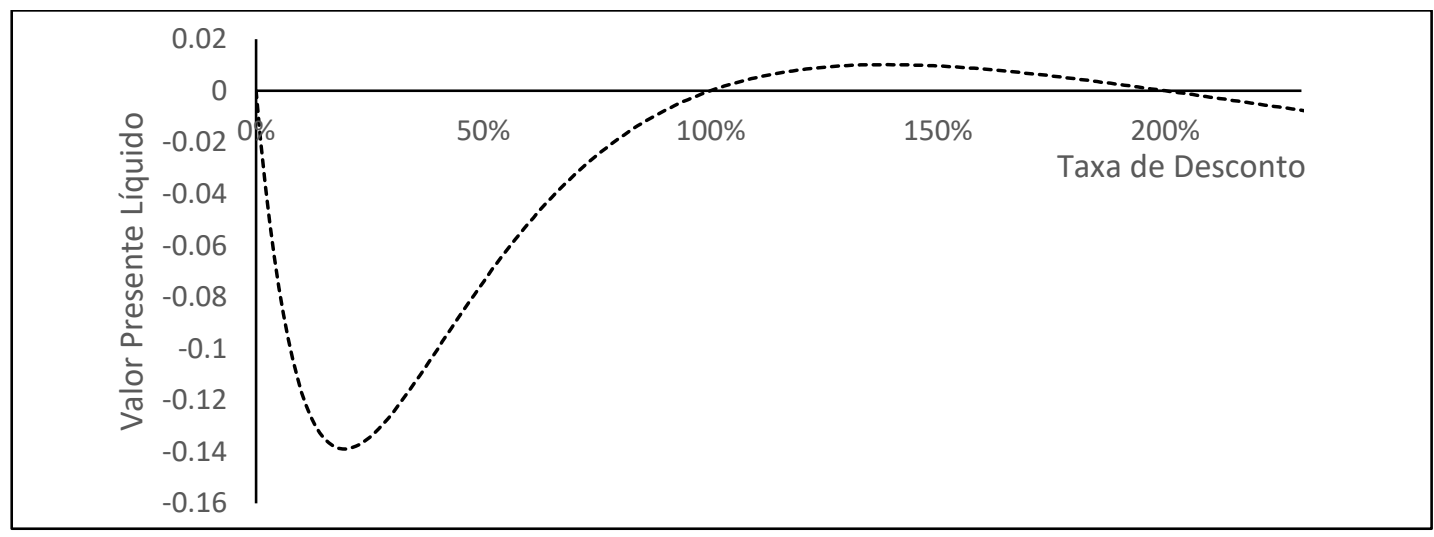

Fonte: adaptado de Hazen (2003). 
Entretanto, adotando a metodologia proposta por Hazen (2003), considerando uma situação em que o custo de capital é de $10 \%$, chega-se aos três fluxos de investimentos indicados na TABELA 12, com seus respectivos resultados de VPL.

\section{Tabela 12 - Exemplo hipotético de solução de múltiplas TIR's: Fluxos de investimento com $k_{i}=$ TIR $_{i}$}

\begin{tabular}{c|ccc|c}
\hline $\mathbf{k}$ & \multicolumn{3}{|c|}{ Fluxos de Investimento } & VPL \\
\hline $0 \%$ & 1 & -5 & 6 & 1,41 \\
\hline $100 \%$ & 1 & -4 & 3 & $-0,16$ \\
\hline $200 \%$ & 1 & -3 & 2 & $-0,07$ \\
\hline
\end{tabular}

Fonte: adaptado de Hazen (2003).

A metodologia implementada por Hazen (2003) consiste, primeiramente, em caracterizar cada fluxo de investimentos obtido. Observando os resultados da Tabela 12, conclui-se que quando $\mathrm{k}=0 \%$ o fluxo de investimentos gerado é caracterizado como um fluxo misto de investimentos possuindo a característica de um investimento líquido (VPL à taxa de mercado é positivo). Quando $\mathrm{k}=100 \%$ ou $200 \%$, o fluxo é igualmente caracterizado como um fluxo misto de investimentos, entretanto, possui a característica de um empréstimo líquido (VPL à taxa de mercado é negativo).

Caracterizados os fluxos gerados, parte-se para a análise de aceitação ou rejeição do fluxo de caixa. Partindo da definição, para investimentos líquidos o projeto deve ser aceito quando o VPL do fluxo de investimentos à taxa de mercado for positivo. Para empréstimos líquidos, o projeto deve ser aceito quando o mesmo for negativo. Observa-se que, no exemplo em questão, a análise isolada de cada fluxo de investimentos calculado sempre leva ao mesmo resultado, de aceitação do projeto. Segundo Hazen (2003), a metodologia sempre traz resultados consistentes e válidos para qualquer um dos possíveis resultados que a metodologia da TIR gerar, sendo a solução para a análise de fluxos de caixa que possuem múltiplas TIR's.

Os esforços por encontrar metodologias que fossem capazes de contornar as aparentes inconsistências da aplicação do método da TIR se intensificaram a partir de então. Merecem destaque tanto autores que propuseram alternativas mais elaboradas, como por exemplo a "Taxa Interna de Retorno Relevante" (Schafrick, 2003), quanto 
autores que elaboraram alternativas mais simples, como, por exemplo, a técnica da paridade da taxa interna de retorno (Zhang, 2005).

Zhang (2005) sugere que, nos casos em que existam múltiplos valores de TIR, deve-se verificar a quantidade de resultados acima da taxa que representa o custo de capital. Se o número de resultados for par, deve-se rejeitar o projeto; para o caso de quantidades ímpares, aceita-se. Conforme detalhado por Zhang (2005), essas considerações se baseiam exclusivamente no comportamento da curva produzida pela relação VPL versus Taxa de desconto.

Ainda nos anos 2000, outros autores desenvolvem estudos que acabaram direcionando as discussões acerca do método para que se chegasse ao entendimento atual. Foram comuns tanto estudos acerca da incompatibilidade entre os métodos do VPL e da TIR, quanto da hipótese de que ocorrem reinvestimentos dos fluxos de caixa implicitamente na formulação da TIR (Tang; Tang, 2003; Basu, 2003; Ben-Horin; Kroll, 2017), além de trabalhos acerca da multiplicidade de resultados ao aplicar-se o método da TIR em fluxos de caixa não convencionais (Hajdasinski, 2004; Ben-Horin; Kroll, 2012).

Estendendo a discussão para a Taxa Interna de Retorno Modificada (TIRM), há que se destacar Cheremushkin (2012), que aponta para a necessidade de um cuidado especial quanto à esta metodologia, no que tange às considerações de reinvestimento na aplicação da TIR. Usando três fluxos de caixa hipotéticos, Cheremushkin (2012) avalia o impacto das duas metodologias, conforme exposto na Tabela 13, onde considerou-se a mesma taxa de desconto e reinvestimento $(10 \%$ a.a.) para o cálculo da TIRM.

Tabela 13 - Fluxos de caixa analisados

\begin{tabular}{|c|c|c|c|c|c|c|c|c|}
\hline Período & Ano 1 & Ano 2 & Ano 3 & Ano 4 & Ano 5 & Ano 6 & Ano 7 & ... Ano 9 \\
\hline $\begin{array}{c}\text { Fluxo de } \\
\text { caixa A }\end{array}$ & $(300,00)$ & 350,00 & 0,01 & 0,01 & 0,01 & 0,01 & & \\
\hline Resultado & & TIRM: & $11,3 \%$ & & TIR: & $16,7 \%$ & & \\
\hline $\begin{array}{l}\text { Fluxo de } \\
\text { caixa B }\end{array}$ & $(300,00)$ & 350,00 & 0,01 & 0,01 & 0,01 & 0,01 & ... & 0,01 \\
\hline Resultado & & TIRM: & $10,8 \%$ & & TIR: & $16,7 \%$ & & \\
\hline $\begin{array}{l}\text { Fluxo de } \\
\text { caixa C }\end{array}$ & $(300,00)$ & 350,00 & 0,01 & 0,01 & & & & \\
\hline Resultado & & TIRM: & $12,2 \%$ & & TIR: & $16,7 \%$ & & \\
\hline
\end{tabular}

Fonte: Cheremushkin (2012). 
Os fluxos de $\$ 0,01$ foram colocados propositalmente como um artifício para analisar a veracidade das métricas, pois fluxos tão pequenos não deveriam impactar significativamente no resultado do retorno global do projeto. Entretanto, verifica-se que a TIRM, devido à sua formulação, sofre um impacto muito grande dessas entradas, ao mesmo tempo em que a TIR praticamente não se altera. Com essa consideração, Cheremushkin (2012) conclui que a TIR apresenta um resultado mais satisfatório do rendimento do projeto.

Atrelado ao fato anteriormente citado, Cheremushkin (2012) rebate uma das maiores críticas ao uso do Método da TIR: que ela considera o reinvestimento das entradas a uma taxa igual à própria TIR. Segundo Cheremushkin (2012), os $\$ 350$ recebidos no ano 2 podem ser reinvestidos a qualquer outra taxa. Entretanto, ao se avaliar levando em consideração o valor do dinheiro no tempo, essa taxa de reinvestimento deve estar presente também no denominador da fórmula. Exemplificando, supondo que as entradas de caixa são reinvestidas a uma taxa de 20\%, para o cálculo da TIR tem-se a Equação (3):

$$
-\sum_{t=0}^{n} \frac{I_{t}}{\left(1+\rho_{t}\right)^{t}}=\sum_{t=1}^{n} \frac{C F_{t} \times(1+0,2)^{n-t}}{(1+T I R)^{t} \times(1+0,2)^{n-t}}
$$

onde, t é o índice de tempo para cada fluxo de caixa, n é o período de duração do fluxo de caixa, $\mathrm{I}_{\mathrm{t}}$ é o fluxo de caixa negativo, no instante t, $\rho_{\mathrm{t}}$ é a taxa de desconto para a saída de caixa ocorrida no instante te $\mathrm{CF}_{\mathrm{t}}$ a entrada de caixa, no instante $\mathrm{t}$.

Nota-se que o termo $(1+0,2)^{\text {n-t }}$ (representando a parcela oriunda do reinvestimento das entradas de caixa) repete-se no numerador e denominador da Equação (3), anulando-se. Desta forma, Cheremushkin (2012) afirma que o método da TIR encontra o rendimento sem admitir possíveis reinvestimentos dos fluxos de caixa intermediários (caso sejam considerados). O ponto discutido é que, na aplicação do método da TIRM, a formulação considera explicitamente reinvestimento dos fluxos de caixa intermediários e, por sua vez, a taxa de reinvestimento não é anulada, conforme Equação (4) (considerando uma taxa de reinvestimento igual a 20\%):

$$
-\sum_{t=0}^{n} \frac{I_{t}}{\left(1+\rho_{t}\right)^{t}}=\sum_{t=1}^{n} \frac{C F_{t} \times(1+0,2)^{n-t}}{(1+T I R M)^{t} \times(1+T I R M)^{n-t}}
$$


Devido a essa incompatibilidade entre os termos $(1+0,2)^{\mathrm{n}-\mathrm{t}}$ do numerador e $(1+\mathrm{TIRM})^{\mathrm{n}-\mathrm{t}}$ do denominador, Cheremushkin (2012) conclui que a abordagem da TIRM é errônea e perigosa, dando maior credibilidade para a aplicação da tradicional TIR visando à avaliação da rentabilidade de projetos. Conclusão semelhante é definida no trabalho de Magni e Martin (2017), onde frisou-se que a TIR de um projeto não deve ser afetada por escolhas de taxas de reinvestimentos externas.

Rich e Rose (2014) apontam para a necessidade de um cuidado especial em relação à abordagem do tema nas salas de aula. Segundo os autores, atualmente está sendo cada vez mais comum o detalhamento da rotina de cálculo da TIR em ferramentas computacionais, enquanto que o completo entendimento do significado dos resultados dessa metodologia de análise está sendo deixado de lado.

Para defender o entendimento de que a TIR é equivalente à taxa que representa a rentabilidade gerada pela sobreposição dos investimentos líquidos e dos fluxos de caixa positivos esperados para o projeto, Rich e Rose (2014) utilizam a mesma técnica posteriormente aplicada por Arjunan e Kannapiran (2017). A técnica consiste na transformação do fluxo de caixa em um Cronograma de Amortização de Capital - CAS (do termo em inglês Capital Amortization Schedule), usando uma abordagem em que os fluxos de caixa, na medida em que ocorrem, vão incorporando um saldo acumulado. Este saldo, por sua vez, pode ser aplicado a determinada taxa de rendimento (Arjunan; Kannapiran, 2017).

A Tabela 14 apresenta o fluxo de caixa de um projeto hipotético definido por Rich e Rose (2014), considerando um investimento inicial de $\$ 77.000$, obtendo fluxos intermediários de $\$ 35.000$ por ano ao longo dos três anos. Observa-se que os valores se encontram com sinais invertidos, a fim de conferir mais lógica à análise sob a ótica de um CAS. No último ano do projeto (ano 3), além do fluxo de caixa obtido, considera-se ainda a existência de um valor residual de $\$ 10.000$.

Tabela 14 - Fluxo de caixa analisado

\begin{tabular}{c|c|c|c|c}
\hline Período & Ano 0 & Ano 1 & Ano 2 & Ano 3 \\
\hline Fluxo de caixa & 77000 & -35000 & -35000 & -35000 \\
\hline Valor Residual & - & - & - & -10000 \\
\hline
\end{tabular}

Fonte: adaptado de Rich e Rose (2014). 
Dessa forma, considera-se que o valor do investimento é gradualmente recuperado em cada período do projeto, conforme apresentado no Tabela 15. Notase que, além da simples soma dos valores dos fluxos intermediários, pode ser considerado o rendimento de uma determinada taxa sobre o saldo incorporado, de maneira análoga ao cálculo dos juros incorridos periodicamente em um empréstimo (Rich; Rose, 2014).

Tabela 15 - Cronograma de amortização de capital considerando a TIR do fluxo como retorno

\begin{tabular}{l|r|r|r|r}
\hline \multicolumn{1}{c|}{ Descrição } & \multicolumn{1}{c|}{ Ano 0 } & \multicolumn{1}{c|}{ Ano 1 } & \multicolumn{1}{c|}{ Ano 2 } & \multicolumn{1}{c}{ Ano 3 } \\
\hline Saldo no Início do Período & 0.000 & 77.000 & 58.931 & 36.889 \\
\hline $\begin{array}{l}\text { ( + ) Retorno obtido pela Aplicação } \\
\text { do Saldo (TIR) }\end{array}$ & 0.000 & 16.931 & 12.958 & 8.111 \\
\hline ( = ) Saldo Parcial & 0.000 & 93.931 & 71.889 & 45.000 \\
\hline ( + ) Fluxo de Caixa do período & 77.000 & -35.000 & -35.000 & -35.000 \\
\hline ( = ) Saldo no Fim do Período & 77.000 & 58.931 & 36.889 & 10.000 \\
\hline
\end{tabular}

Fonte: adaptado de Rich e Rose (2014).

Não coincidentemente, o valor terminal do CAS (saldo no fim do ano 3) se iguala ao valor residual do projeto. Este resultado é possível apenas quando a taxa considerada é a TIR do fluxo de caixa em questão. Para Rich e Rose (2014) e Arjunan e Kannapiran (2017), esse fato é suficiente para indicar que a metodologia da TIR não considera reinvestimento dos fluxos de caixa, mas sim que indica o retorno intrínseco ao fluxo gerado pelo projeto em análise, conforme sugere sua definição.

\section{Considerações finais}

A preocupação em criar um modelo matemático que possibilite avaliar as opções de investimento, levando em consideração o retorno projetado do capital investido de maneira coerente, nasceu na época da Revolução Industrial (Parker, 1968) e se mantém viva. O desenvolvimento das técnicas de análise de viabilidade acentuou-se sobretudo no século XX, em grande parte com os estudos de Fisher (1907), Boulding (1935) e Keynes (1936), que serviram de base para a elaboração de uma série de estudos e discussões posteriores. 
Embora os conceitos tenham sido criados há tempos e amplamente discutidos ao longo dos anos, em se tratando especificamente da metodologia da TIR como indicador de viabilidade, ainda permanecem presentes na literatura discussões relativas à definição de limitações na metodologia. Entretanto, vários são os argumentos de que o método traz resultados coerentes e que até mesmo quando ocorrem múltiplos resultados existem meios sólidos de avaliar a viabilidade do projeto. Vale ressaltar que em qualquer análise utilizando o método faz-se necessária a consideração do custo de capital para averiguar a aceitação ou rejeição do(s) projeto(s) em análise.

Embora os estudos aqui citados apontem para a consistência do método da TIR, é importante ressaltar que o método não deve ser o único indicador de viabilidade utilizado para a análise de investimentos, como já sinalizado por Parker (1968). Para se realizar uma avaliação completa e adequada, faz-se necessário utilizar outros métodos em conjunto, visando estabelecer uma análise que englobe as singularidades de cada projeto.

\section{Referências}

ARJUNAN, K. C.; KANNAPIRAN, K. Cost-benefit analysis and the controversial reinvestment assumption in IRR and NPV estimates: some new evidence against reinvestment assumption. Economic Papers, v. 36, n. 3, p. 351-363, 2017.

BASU, U. K. A consistent way towards investment decisions. Trabalho apresentado na $5^{\text {a }}$ GLOBAL CONFERENCE OF ACTUARIES, Nova Delhi, 2003.

BEN-HORIN, M.; KROLL, Y. The limited relevance of the multiple IRRs. The Engineering Economist, v. 57, n. 2, p. 101-118, 2012.

BEN-HORIN, M.; KROLL, Y. A simple intuitive NPV-IRR consistent ranking. Quarterly Review of Economics and Finance, v. 66, n. 1, p. 108-114, 2017.

BÖHM-BAWERK, E. Recent literature on interest 1884-1899. Londres: Macmillan, 1903.

BOULDING, K. E. The theory of a single investment. Quarterly Journal of Economics, v. 49, n. 3, p. 475-494, 1935.

CASAROTTO FILHO, N; KOPITTKE, B. Análise de investimentos, São Paulo: Atlas, 1994. 
CHEREMUSHKIN, S. V. There is no hidden reinvestment assumption in discounting formula and IRR: logical and mathematical arguments. SSRN Eletronic Journal, p. 1-21, 2017.

DUDLEY JR., C. Note on reinvestment assumptions in choosing between net present value and internal rate of return. Journal of Finance, v. 27, n. 4, p. 907-915, 1972.

FISHER, I. The rate of interest: its nature, determination and relation to economic phenomena. Nova Iorque: The Macmillan Company, 1907.

GEISST, C. Beggar thy neighbor: a history of usury and debt. Filadélfia: University of Pennsylvania Press, 2013.

HAJDASINSKI, M. Technical note - the internal rate of return (IRR) as a financial indicator. The Engineering Economist, v. 49, n. 2, p. 185-197, 2004.

HAZEN, G. A new perspective on multiple internal rates of return. The Engineering Economist, v. 48, n. 1, p. 31-51, 2003.

HOMER S; SYLLA, R. A history of interest rates. Nova Jersey: John Wiley \& Sons, 2005.

KEYNES, J. M. The General Theory of Employment, Interest, and Money. Londres: Macmillan, 1936.

KLAMMER, T. Empirical evidence of the adoption of sophisticated capital budgeting techniques. Journal of Business, v. 45, n. 3, p. 387-397, 1972.

KREGEL, J. Irving Fisher, great-grandparent of the General Theory: money, rate of return over cost and efficiency of capital. Cahiers d'Économie Politique, v. 1, n. $14-15$, p. 59-68, 1988.

LIN, S. The modified internal rate of return and investment criterion. The Engineering Economist, v. 21, n. 4, p. 237-247, 1976.

LORIE, J.; SAVAGE, L. Three problems in rationing capital. Journal of Business, v. 28, n. 4, p. 229-239, 1955.

MAGNI, C.; MARTIN, J. The reinvestment rate assumption fallacy for IRR and NPV: A pedagogical note. SSRN Eletronic Journal, p. 1-9, 2018.

MARSHALL, A. Principles of economics. Hampshire: Palgrave Macmillan, 1907. 
NEUGEBAUER, O. The exact sciences in antiquity. Nova Iorque: Dover Publications, 2005.

PARKER, R. Discounted cash flow in historical perspective. Journal of Accounting Research, v. 6, n. 1, p. 58-71, 1968.

RAPP, B. The internal rate of return method - a critical study. Engineering Costs and production Economics, v. 1, n. 5, p. 43-52, 1980.

RENSHAW, E. A note on the arithmetic of capital budgeting decisions. Journal of Business, v. 30, n. 3, p. 193-201, 1957.

RICH, S.; ROSE, J. Re-examining an old question: does the IRR method implicitly assume a reinvestment rate? Journal of Financial Education, v. 40, n. 1/2, p. 152-166, 2014.

RYAN, P; RYAN, G. Capital budgeting practices of the fortune 1000: how have things changed? Journal of Business and Management, v. 8, n. 4, p. 355-364, 2002.

RYBA, A.; LENZI, E.; LENZI, M. Elementos de engenharia econômica. Curitiba: Editora Intersaberes, 2016.

SAMUELSON, P. Some aspects of the pure theory of capital. Quarterly Journal of Economics, v. 51, 1937.

SCHAFRICK, I. Analyzing multiple internal rates of return. 2003. $35 \mathrm{f}$. Tese (Mestre em Engenharia Industrial). Lehigh University, Bethlehem, 2003.

SCHALL, L.; SUNDEM, G.; GEIJSHEEK JR., W. Survey and analysis of capital budgeting methods. Journal of Finance, v. 33, n. 1, p. 281-287, 1978.

SHULL, D. Interpreting rates of return: a modified rate of return approach. Financial Practice and Education, v. 3, n. 2, p. 67-71, 1993.

SOLDOFSKY, R. A note on the history of bond tables and stock valuation models. Journal of Finance, v. 21, n. 1, p. 103-111, 1966.

SOLOMON, E. The arithmetic of capital-budgeting decisions. Journal of Business, v. 29, n. 2, p. 124-129, 1956.

TANG, S.; TANG, H. The variable financial indicator irr and the constant economic indicator NPV. The Engineering Economist, v. 48, n. 1, p. 69-78, 2003. 
WELLINGTON, A. The economic theory of the location of railways. Nova Iorque: John Wiley \& Sons, 1887.

ZHANG, D. A different perspective on using multiple internal rates of return: the IRR Parity technique. The Engineering Economist, v. 50, n. 4, p. 327-335, 2005. 